\title{
VARIATIONS IN THE ORIGIN OF GONADAL ARTERY AND ITS CLINICAL SIGNIFICANCE
}

\section{Amita Sarkar *1, Puloma Chakraborty ${ }^{2}$.}

${ }^{{ }_{1} 1}$ Assistant Professor, Department Of Anatomy, K.P.C. Medical College and Hospital 1F, Raja S. C. Mullick Road, Jadavpur, Kolkata, India. - 700032

${ }^{2}$ Demonstrator, Department Of Anatomy, K.P.C. Medical College and Hospital, 1F, Raja S. C. Mullick Road, Jadavpur, Kolkata, India.

\section{ABSTRACT}

Background: A sound knowledge of variations of blood vessels is required during operative, diagnostic and endovascular procedures in the abdomen and pelvis. The anatomy of the gonadal vessels has assumed more importance with development of newer intra-abdominal operative and laparoscopic techniques. The main aim of this study is to highlight incidence of variable origin of gonadal artery and its clinical significance.

Materials and Methods: Dissection of posterior abdominal wall was done in 30 cadavers in the department of Anatomy, K.P.C. Medical College and Hospital, Kolkata to observe the origin and course of gonadal arteries.

Results: Variation was found in two cases (6.67\%). Both of the cases were in male (8.33\%) and on the left side.

Conclusion: Various morphological anomalies of gonadal arteries are reported. The possible embryological basis for this variation as well as its clinical significance, are discussed. The knowledge of this variation will help the radiologists and surgeons in avoiding clinical complications during uroradiologic interventions and surgical procedures such as renal and gonadal surgeries.

KEY WORDS: Gonadal artery, Testicular artery, Ovarian artery, Accessory renal artery

Address for Correspondence: Department Of Anatomy, K.P.C. Medical College and Hospital, 1F, Raja S.C. Mullick Road, Jadavpur, Kolkata - 700032, India. Contact no: 9088383680

E-Mail: amita_sarkar@yahoo.com,dramitasarkar3@gmail.com

Access this Article online

Quick Response code

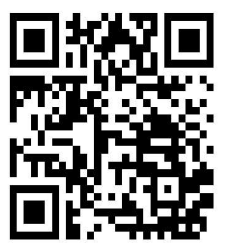

DOI: $10.16965 /$ ijar.2018.332

Journal Information

International Journal of Anatomy and Research

ICV for 2016
$\mathbf{9 0 . 3 0}$ $\begin{gathered}\text { ISSN (E) 2321-4287 | ISSN (P) 2321-8967 } \\ \text { https://www.ijmhr.org/ijar.htm }\end{gathered}$

DOI-Prefix: https://dx.doi.org/10.16965/ijar

\section{Article Information}

Received: 22 Jul 2018

Peer Review: 23 Jul 2018

Revised: None
Accepted: 06 Sep 2018

Published (O): 10 Oct 2018

Published (P): 10 Oct 2018

\section{INTRODUCTION}

The gonadal arteries are two long slender vessels that usually arise from the anterolateral or lateral aspect of the abdominal aorta a little inferior to the renal arteries. The vertebral level of their origin varies from the level of first to third lumbar vertebrae [1]. Each passes inferolaterally under the parietal peritoneum on psoas major [2].

In addition to the normal pattern, several other sites of origin of the gonadal arteries have been described; among them the renal, accessory renal and suprarenal arteries are most commonly mentioned $[3,4,5]$ and more rarely the lumbar, common or internal iliac and superior epigastric arteries [3,6,7].

Anatomy of testicular artery has been well studied because of its importance in testicular physiology, and testicular and renal surgery. Each testicular artery passes obliquely downwards and posterior to the peritoneum on the psoas major muscle, and enters the inguinal canal 
through the deep inguinal ring. Along their course, the testicular arteries are accompanied by the testicular veins. They pass through the deep inguinal ring of the corresponding side and then become constituents of the spermatic cord and terminate in the gonads, which they supply [2].

Each ovarian artery descends behind the peritoneum, and crosses the external iliac artery and vein to enter the true pelvic cavity, enters in the suspensory ligament of ovary and splits into a branch that supplies ovary and another branch that supplies uterine tube. On each side, a branch passes lateral to the uterus to unite with the uterine artery, other branches accompany the round ligaments through the inguinal canal and supply the skin of the labium majus and inguinal region [2].

Explanation for individual or combined variations of renal and gonadal arteries had been related to the embryological development of both vessels from the lateral mesonephric branches of the dorsal aorta [8]. Such variations of the gonadal and renal arteries have clinical and surgical significance with respect to their potential influence on the blood flow to the kidney and the gonads and to the haemorrhagic complications following retroperitoneal operations. As the invasive interventions such as renal transplantation, interventional radiologic procedures and urologic operations increase, awareness of the possible variations of the renal and gonadal arteries is necessary for adequate surgical management in the aforementioned specialties $[5,6]$.

\section{MATERIALS AND METHODS}

The present study was done in 30 formalin preserved cadavers ( 24 males and 6 females) in the department of Anatomy, K.P.C. Medical College and Hospital, Kolkata to observe the variation in the origin and course of the gonadal arteries of both sides. The abdominal cavity was opened by routine dissection procedure and the retroperitoneal structures were exposed. Cadavers with abdominal pathology like malignancies were excluded from the study. The connective tissue surrounding the kidneys and great vessels and their branches and tributaries were removed to provide a clear field of vision. The gonadal arteries were observed in particular for their origin, course and branches. Appropriate measurements were taken, the specimens were photographed and the findings were appropriately documented.

\section{RESULTS}

The present study showed variation in the origin of gonadal artery in 2 cadavers (6.67\%) out of 30 cadavers. Both the variations were found in male, and no variation was present in female, and both of them were on the left side. Therefore, origin of testicular artery showed variation in 2 out of 24 cadavers (8.33\%) and ovarian artery showed no variation (Table 1 ).

Table 1: Incidence of variation in the origin of gonadal artery.

\begin{tabular}{|c|c|c|}
\hline Sex & Side & Variation \\
\hline \multirow{2}{*}{ Male (24) } & $\begin{array}{c}\text { Right } \\
\text { Left }\end{array}$ & $\begin{array}{c}0(0 \%) \\
2(8.33 \%)\end{array}$ \\
\hline \multirow{2}{*}{ Female (6) } & Right & $0(0 \%)$ \\
& Left & $0(0 \%)$ \\
\hline \multirow{2}{*}{ Total (30) } & Right & $0(0 \%)$ \\
& Left & $2(6.67 \%)$ \\
\hline
\end{tabular}

Fig. 1: Origin of left testicular artery from left lower polar accessory renal artery.

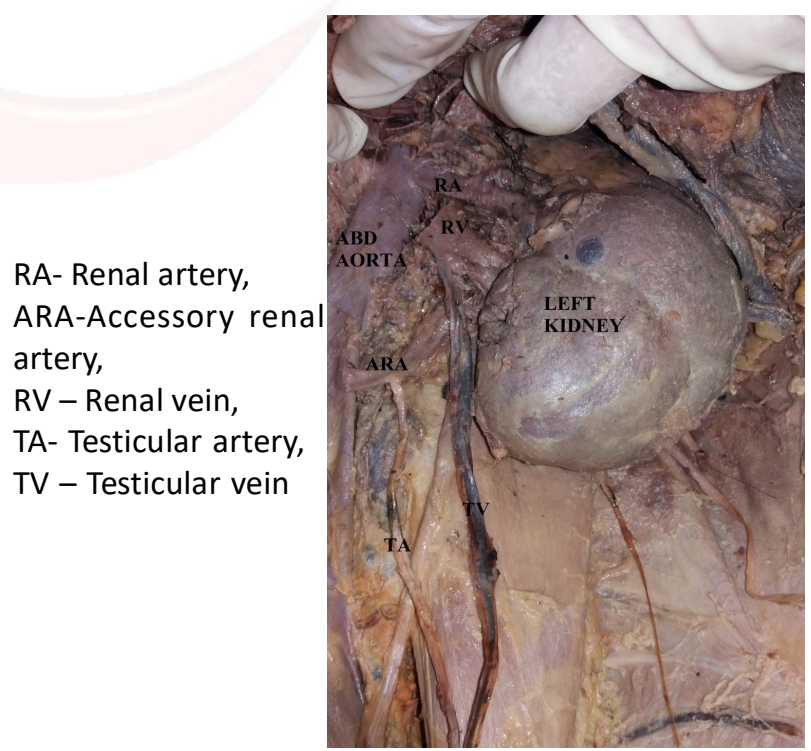

In these two cadavers, left testicular artery took origin from left lower polar accessory renal artery (figure $\mathbf{1}$ and $\mathbf{2}$ ). Besides variations in the origin, the course of the gonadal arteries, were normal otherwise. Each testicular artery passed obliquely downwards, posterior to the peritoneum on the psoas major muscle, and entered the inguinal canal through the deep inguinal ring. Along their course, the testicular arteries were 
accompanied by the testicular veins. No branches were given by the testicular artery in the abdomen. Ovarian artery showed no variation regarding its origin, course or branching pattern.

Fig. 2: Origin of testicular artery from accessory renal artery

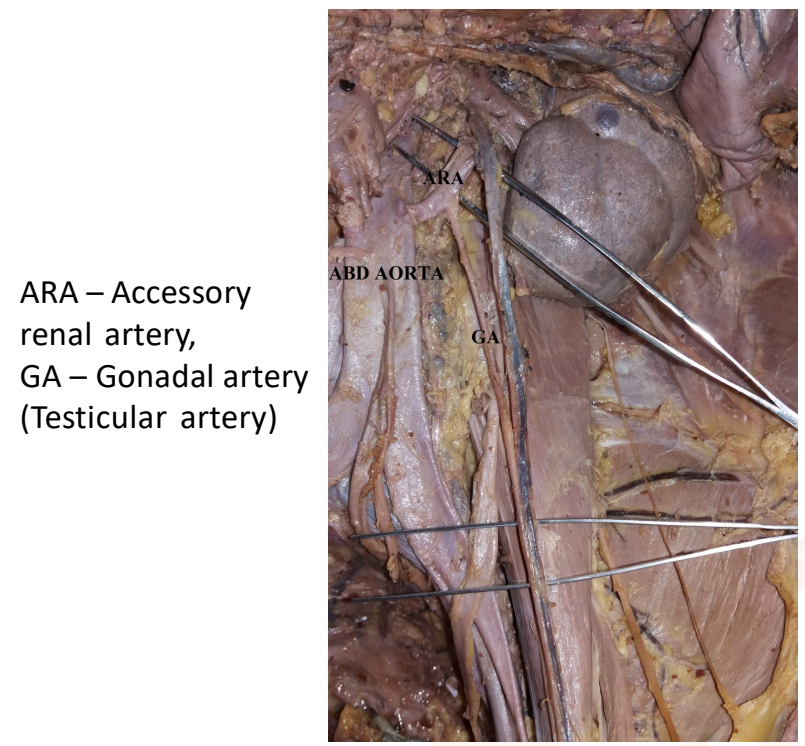

Fig. 3: Origin of gonadal artery from abdominal aorta

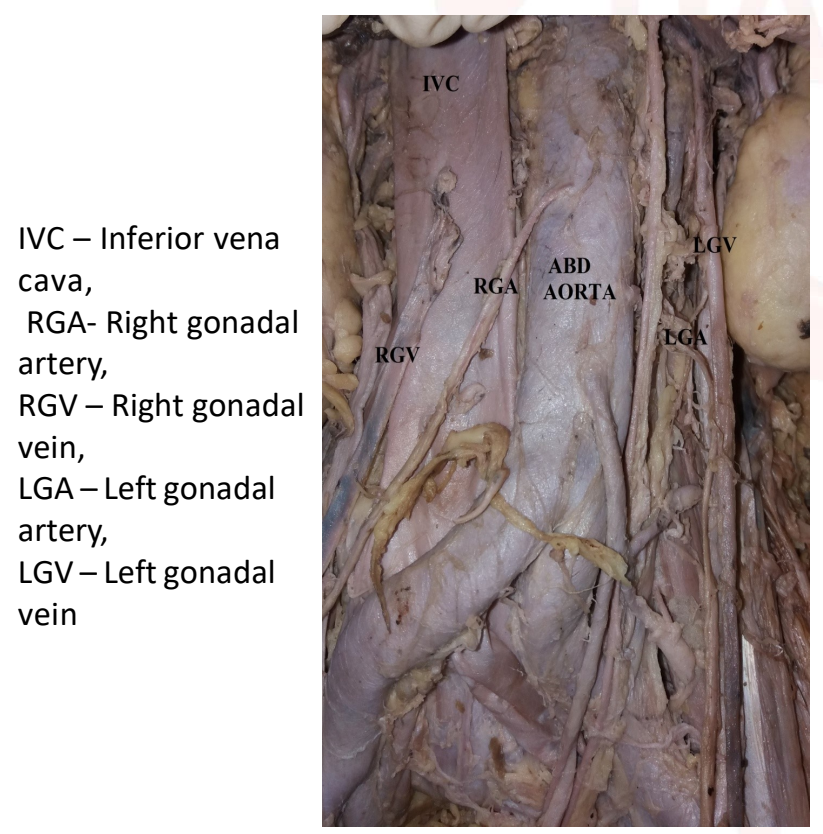

\section{DISCUSSION}

The variations of gonadal arteries concern deviations in their origin, course and number. They may be unilaterally or bilaterally doubled, tripled, or even quadrupled [6] and they may arise from a common stem with the suprarenal arteries [1]. The normal pattern according to classical anatomical textbook is followed in the $83 \%$ of the cases [3], while several studies report anomalies in their origin with an incidence, which range from $4.7 \%$ [4] to $75 \%$ [9].
More specifically, the gonadal arteries are reported to arise from the main renal arteries with a frequency, which varies from $1.47 \%$ [9] to $17 \%$ [3], while their origin from an accessory renal artery ranges from 5.5\% [5] to $31.25 \%$ [9]. The latter is recorded to occur bilaterally only in the $1.1 \%$ of the total cases [5]. In our study the origin of gonadal artery from accessory renal artery was present in $6.67 \%$ cases. The testicular arteries tend to present anomalous origin more often $(15.5 \%)$, than the ovarian arteries (2.2\%) [5].The present study also showed a similar finding (anomalous origin of testicular artery in $8.33 \%$ and ovarian artery $0 \%$ ).

An accessory left testicular artery from the descending aorta has been reported by Loukas and Stewart [10].Left testicular artery originating behind the left renal vein at the level of the left renal artery from the abdominal aorta, and getting entrapped between the two divisions of the left renal vein, has been reported by Satheesha [11]. The persistence of cranial lateral mesonephric artery results in a high origin of the gonadal artery, probably from suprarenal or from a more superior aortic level studied by Salve et al. [12].

Variations of renal and gonadal vessels have an embryological basis. The developing mesonephros, metanephros, suprarenal glands and gonads are supplied by nine pairs of lateral mesonephric arteries arising from the dorsal aorta. These arteries are divided into three groups viz: the first and second arteries, the third to fifth and the sixth to ninth arteries constitute the cranial, middle and caudal group respectively. The middle group gives rise to the renal arteries. Persistence of more than one artery of the middle group results in multiple renal arteries $[13,14]$. The accessory renal artery could therefore be a result of a persistent lateral mesonephric artery from the middle group. Gonadal arteries can arise from any of these nine mesonephric arteries though they usually arise from the caudal group [14]. In the present study, the origin of the left testicular artery from the lower polar accessory renal artery suggests the embryologic origin of this vessel from the middle group.

The anatomy of gonadal arteries has assumed importance because of development of new 
operative techniques within abdominal cavity for operations like varicocoele and undescended testis. During laparoscopic surgery of male abdomen and pelvis many complications occur due to unfamiliar anatomy in operative field. Thus it becomes imperative to carefully preserve the gonadal artery in order to prevent any vascular insults to gonad, as the gonadal artery being its unique source of blood supply.

\section{CONCLUSION}

Knowledge of variations of blood vessels in the renal hilar region is important during operative, diagnostic and endovascular procedures in the abdomen. Variations of the renal and testicular artery should be considered in order to prevent acute hemorrhage due to their injury in renal hilar dissections and retroperitoneal surgical explorations. Due to the increased demand for living donor graft in renal transplants, the knowledge of such variant anatomy of the renal and gonadal arteries is an important prerequisite to successful renal transplantation and as such comprehensive arteriography of these vessels before surgery is recommended. The origin of the testicular artery from the renal artery should be noted as injury to this vessel may result in testicular infarction [15]. The knowledge about these variations is of utmost importance to the urologist, surgeons dealing with kidney retrieval and transplantation, radiologists, persons performing various endourologic procedures and various interventional techniques. Anatomical knowledge of testicular artery is very essential for performing operative techniques of treating varicocele and undescended testes within the abdominal cavity.

\section{Conflicts of Interests: None}

\section{REFERENCES}

[1]. Adachi, B. Das Arteriensystem der Japaner II. Kyoto und Tokyo, Maruzen Publishing Co, 1928.
[2]. Standring, S.; Borley, N. R.; Collins, P.; Crossman, A. R.; Gatzoulis, M. A., Healy, J. C.; Johnson, D.; Mahadevan, V.; Newell, R. L. M. \& Wigley, C. B. Gray's anatomy. The anatomical basis of clinical practice. Edinburgh, Elsevier, 2008.

[3]. Lippert, H. \& Pabst, R. Arterial variations in man. Classification and frequency. Munich, J. F. Bergmann, 1985.

[4]. Asala, S, Chaudhary, S. C., Masumbuko-Kahamba, N. \& Bidmos, M. Anatomical variations in the human testicular blood vessels. Ann. Anat.,2001;183(6):545-9.

[5]. Cicekcibasi, A. E., Salbacak, A., Seker, M.; Ziylan, T., Büyükmumcu, M. \& Uysal, I. I. The origin of gonadal arteries in human fetuses: anatomical variations. Ann. Anat., 2002;184(3):275-9.

[6]. Bergman, R. A.; Afifi, A. K. \& Miyauchi, R. Illustrated Encyclopedia of Human Anatomic Variation. 2006. Available in: http://www.anatomyatlases.org/ AnatomicVariants/AnatomyHP.shtml

[7]. Paraskevas, G. K, loannidis, O, Raikos, A., Papaziogas, B., Natsis, K., Spyridakis, I. \& Kitsoulis, P. High origin of a testicular artery: a case report and review of the literature. J. Med. Case Rep., 2011;5:75.

[8]. Felix W. Mesonephric arteries (aa. mesonephricae). In: Kiebel F, Mall FP eds. Manual of human embryology Vol 2. Philadelphia, Lippincott. 1912; 820825

[9]. Petru, B., Elena, S., Dan, I. \& Constantin, D. The morphology and the surgical importance of the gonadal arteries originating from the renal artery. Surg. Radiol. Anat., 2007;29(5):367-71.

[10]. Loukas M, Stewart D; A case of an accessory testicular artery. Folia Morphol., 2004; 63: 355-357.

[11]. Satheesha NB; Abnormal course of left testicular artery in relation to an abnormal left renal vein: $A$ case report. Kathmandu Univ Med J., 2007; 5: 108109.

[12]. Salve VM, Ashalatha K, Sawant S, Gajendra K; Variant origin of right testicular artery: a rare case. Int J Anat Variat., 2010; 3: 22-24.

[13]. Kocabiyik N, Yalcin B, Yazar F, Ozan H. 2004. A persistent mesonephric artery: a rudimentary accessory renal artery. Gazi Med J 15: 75-8.

[14]. Shoja, M. M.; Tubbs, R. S.; Shakeri, A. B. \& Oakes, W. J. Origins of the gonadal artery: embryologic implications. Clin. Anat., 20(4):428-32, 2007.

[15]. Siniluoto TM, Hellstrom PA, Paivansalo MJ, Leinonen AS. 1998. Testicular infarction following ethanol embolization of a renal neoplasm. Cardiovasc Intervent Radiol 11:162-164.

How to cite this article:

Amita Sarkar, Puloma Chakraborty. VARIATIONS IN THE ORIGIN OF GONADAL ARTERY AND ITS CLINICAL SIGNIFICANCE. Int J Anat Res 2018;6(4.1):5747-5750. DOI: 10.16965/ijar.2018.332 